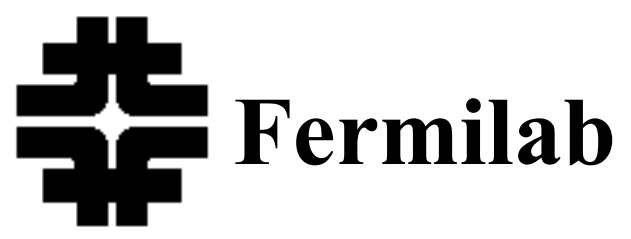

Fermi National Accelerator Laboratory Technical Division

SRF Development Department

P.O. Box 500

Batavia, IL 60510

Fax: (630) 840-8036

\title{
Infrastructure Development of Single Cell Testing Capability at A0 Facility
}

\section{Prepared By: Nandhini Dhanaraj}

\author{
18-Sep-09
}

(Refer to acknowledgment for more elaborate list of personnel) 


\section{Table of Contents}

Abstract

Introduction

Design of Vertical Insert.

RF Test Station.

Temperature Mapping System

Radiation Considerations

High Pressure Rinse System.

Commissioning.

Summary Note

Acknowledgement

References

Appendix A: Proposals and disclaimers submitted to safety panels... 14

A. 1

Pressure rating of top plate vacuum components

A0 north cave operation for $1.3 \mathrm{GHz}$ single-cell R\&D

Appendix B: Recommendations and approvals from safety panels ... 17

B.1

AD Radiation safety review recommendation

B. 2

Initial recommendation from cryogenic safety panel

Division head authorization for initial testing

B.4 Recommendation for operation with active pumping from

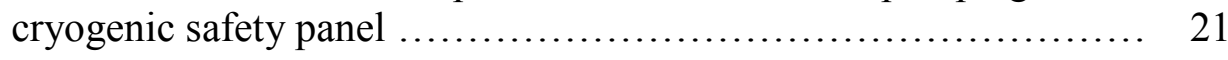

B.5 Division head authorization for testing with active pumping .

\section{List of Figures}

Figure 1 Illustration of the various components of the infrastructure........... 1

Figure 2 Current configuration of the vertical insert .................... 4

Figure $3 \quad$ Lifting fixture for the vertical test stand $\ldots \ldots \ldots \ldots \ldots \ldots \ldots \ldots \ldots \ldots$

Figure 4 Circuit diagram of the RF system $\ldots \ldots \ldots \ldots \ldots \ldots \ldots \ldots \ldots \ldots \ldots \ldots$ 
Figure 5 (a) Attenuation for given power coupling (b) Discretization of power probe tip (c) Attenuation for given transmitted coupling (d) Discretization of transmitted probe tip (e) Q vs power probe length (f) $Q_{\text {ext }}$ vs field probe length .................................. 7

Figure 6 A single G10 board with diode sensors attached showing the 8

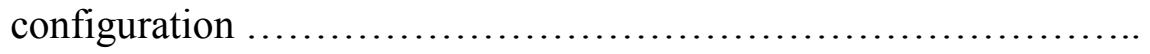

Figure 7 The temperature mapping fixture showing all the sensors installed.. 9

Figure 8 The temperature mapping system installed on a cavity ready to be 9

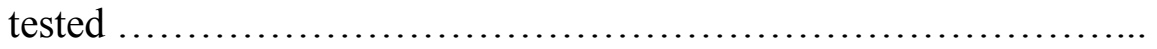

Figure $9 \quad$ High pressure rinse of clear plastic model cavity ................. 10

Figure 10 Cavity test result with no active pumping $Q$ vs Eacc .............. 11

Figure 11 Result comparisons with prior test at IB1 ................... 12 


\begin{abstract}
:
The objective of this technical note is to document the details of the infrastructure development process that was realized at the A0 photo injector facility to establish RF cold testing capability for $1.3 \mathrm{GHz}$ superconducting niobium single cell cavities. The activity began the last quarter of CY 2006 and ended the first quarter of CY 2009.
\end{abstract}

\title{
1.0 Introduction:
}

The whole process involved addressing various aspects such as design of vertical insert and lifting fixture, modification of existing RF test station and design of new couplers, development of a Temperature Mapping (T-Map) system, radiation considerations for the test location (north cave), update of existing High Pressure Rinse (HPR) system, preparation of necessary safety documents and eventually obtaining an Operational Readiness Clearance (ORC). Figure 1 illustrates the various components of the development process.

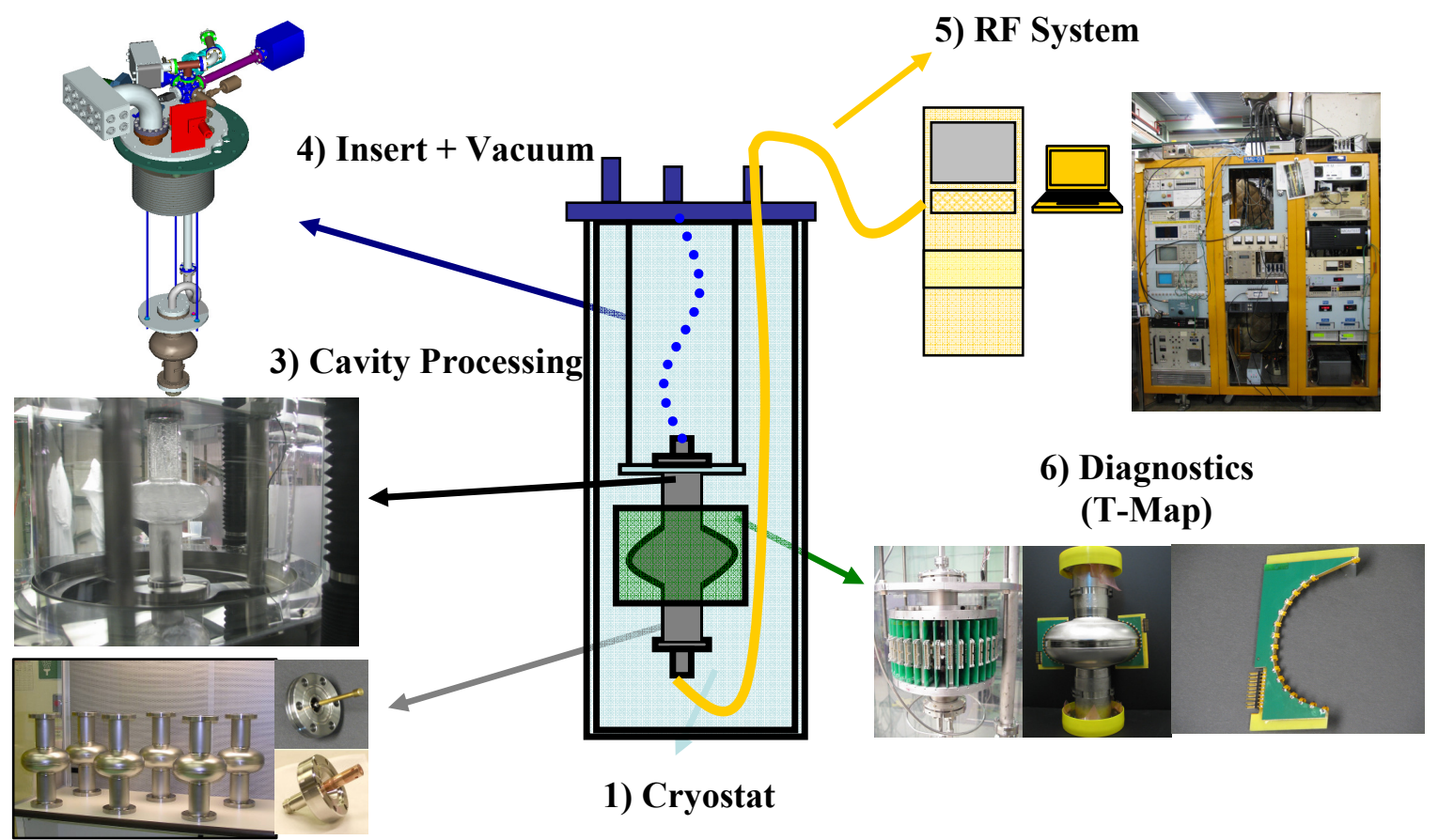

2) Cavities \& Couplers

Figure 1 Illustration of the various components of the infrastructure 
In the past, the north cave test station at A0 has supported the cold testing 3.9 $\mathrm{GHz}$ nine cell [1] and single cell cavities, thus some of the components were available for use and some needed modification. The test dewar had the capacity to accommodate 1.3 GHz single cells although a new vertical insert that could handle both cavity types (1.3 and $3.9 \mathrm{GHz}$ ) had to be designed. The existing cryogenic system with an average capacity of $\sim 0.5 \mathrm{~g} / \mathrm{sec}$ was deemed sufficient. The RF system was updated with broadband components and an additional amplifier with higher power capacity to handle higher gradients usually achieved in $1.3 \mathrm{GHz}$ cavities. The initial testing phase was arbitrated to proceed with fixed power coupling.

A new temperature mapping system was developed to provide the diagnostic tool for hot spot studies, quench characterization and field emission studies. The defining feature of this system was the use of diode sensors instead of the traditional carbon resistors as sensing elements. The unidirectional current carrying capacity (forward bias) of the diodes provided for the ease of multiplexing of the system, thus substantially reducing the number of cables required to power the sensors. The high gradient capacity of the $1.3 \mathrm{GHz}$ cavities required a revision of the radiation shielding and interlocks. The cave was updated as per the recommendations of the radiation safety committee.

The high pressure rinse system was updated with new adapters to assist the rinsing $1.3 \mathrm{GHz}$ single cell cavities. Finally, a proposal for cold testing $1.3 \mathrm{GHz}$ single cell cavities at A0 north cave was made to the small experiments approval committee, radiation safety committee and the Tevatron cryogenic safety sub-committee for an operational readiness clearance and the same was approved. The project was classified under research and development of single cell cavities (project 18) and was allocated a budget of \$200,000 in FY 2007.

\subsection{Design of Vertical Insert:}

A vertical insert/test stand was designed and fabricated to act as the framework supporting the cavity under test and a compact pumping station that could actively pump on the cavity to help maintain ultra high vacuum levels in the cavity during the course of the test. The test stand was designed to support both $1.3 \mathrm{GHz}$ single cells and $3.9 \mathrm{GHz}$ nine and single cells. Provisions were made in the design to accommodate an actuator 
motor drive mechanism on the top plate that would provide the instrumentation for the variable coupler. Figure 2 shows the current version of the test stand which complies with the safety committee's recommendation.

The connector tree provides the outlet for all the electrical connections except for the RF power and transmitted couplers. The vacuum system with active pumping capability includes a turbo molecular pump that enables to maintain high vacuum and an ion pump that helps achieve and maintain an ultra high vacuum level in the system being pumped, namely the cavity and piping and also a residual gas analyzer (RGA) to help detect any leaks. As a safety precaution in the event of a helium leak into the cavity, a burst disk is provided in the relief line which is vented outside the cave. There are 2 configuration locks one on the variable leak valve and the other on the right angle valve to the turbo pump to prevent any back pressure to the helium space and also the pumping system to avoid possible component and personnel damage. Several feedthroughs have been welded to the top plate to provide routing for power and transmitted coupler cables (not shown in figure 2) and also to other applications as the need may arise. The baffles which consist of alternate layers of foam and MLI provide the necessary insulation against heat leak into the test space. The vacuum piping to the cavity accommodates two stainless steel bellows to allow for thermal expansion differences. The cavity itself is held loosely around the neck of the flange to allow for thermal expansion during cool down and warm up cycles and also to compensate for Lorentz forces.

The top plate itself was successfully pressure tested and complies with FESHM 5031 for pressure vessel safety. The engineering note for the pressure vessel safety exists as amendment no. 5 for vessel number RSB 532 [2].

The spread of the different components on the top plate of the vertical insert created an imbalance in the weight distribution causing the test stand to tilt whilst being inserted into the dewar. To address this issue a lifting fixture (figure 3) was designed to provide flexible pick points that would also predictably accommodate future modifications to the top plate design. The lifting fixture was successfully load tested and more details can be found in the engineering specification 5520.000-ES-371061 [3]. 
TD-09-022

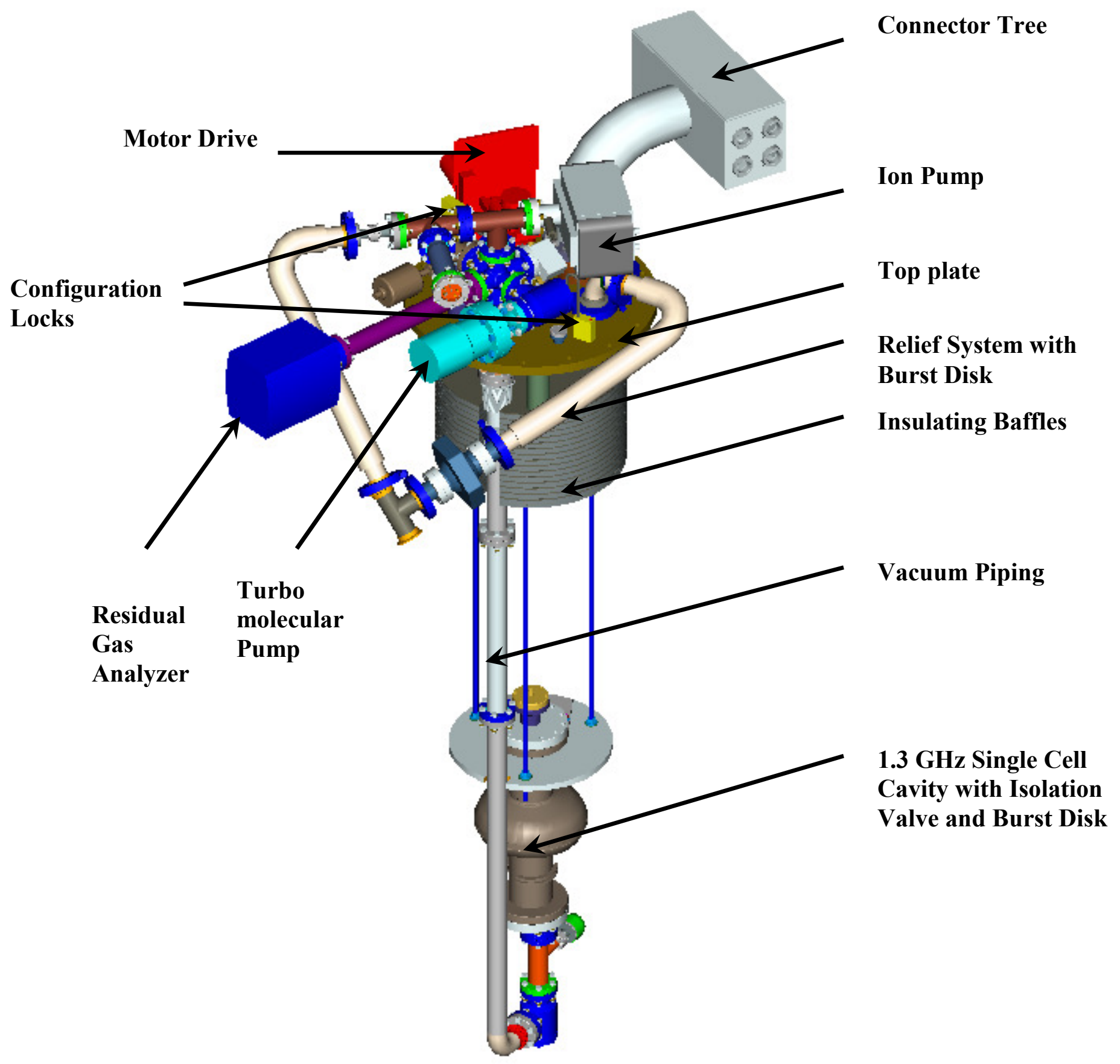

Figure 2 Current configuration of the vertical insert (dwg. 5525.000-ME-442968) 
TD-09-022

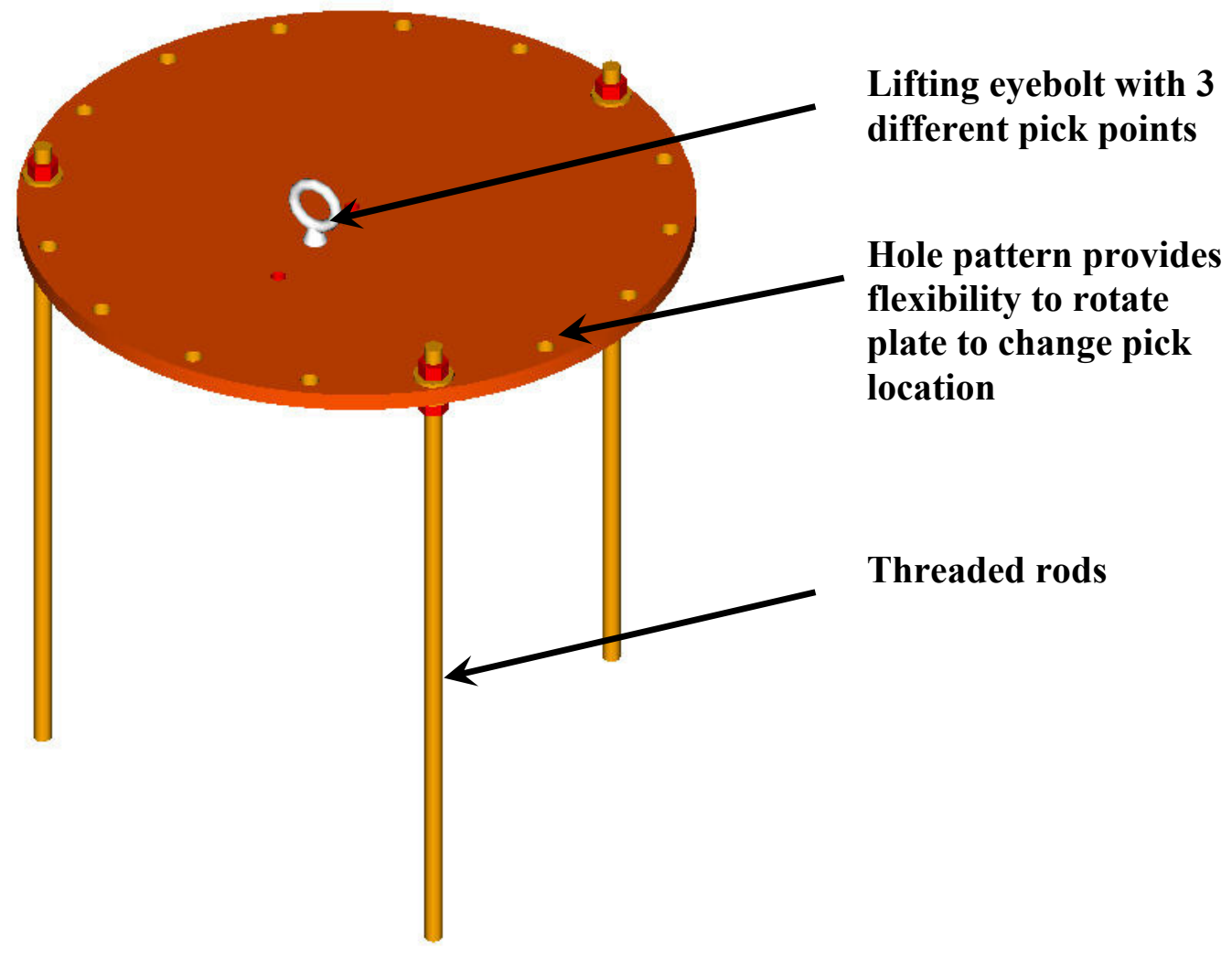

Figure 3 Lifting fixture for the vertical test stand

\subsection{RF Test Station:}

The existing RF test station was modified to allow $1.3 \mathrm{GHz}$ testing capabilities. A fair number of the components were replaced with ones supporting broadband to span over both 1.3 and $3.9 \mathrm{GHz}$ frequencies. A solid state $500 \mathrm{~W}$ amplifier was added in parallel to the existing traveling wave tube (TWT) amplifier. As shown in figure 4 the power supply was partitioned to provide 2 paths, one for $3.9 \mathrm{GHz}$ and the other for $1.3 \mathrm{GHz}$ cavities. A patch panel was installed in the power supply circuit to allow switching between $1.3 \mathrm{GHz}$ and $3.9 \mathrm{GHz}$ inputs. As and when required the attenuators would be changed manually. A new LABVIEW program was implemented to read data. The power coupler was designed to provide fixed coupling, the HFSS simulations were performed to deduce the antenna length (shown in figure 5). 


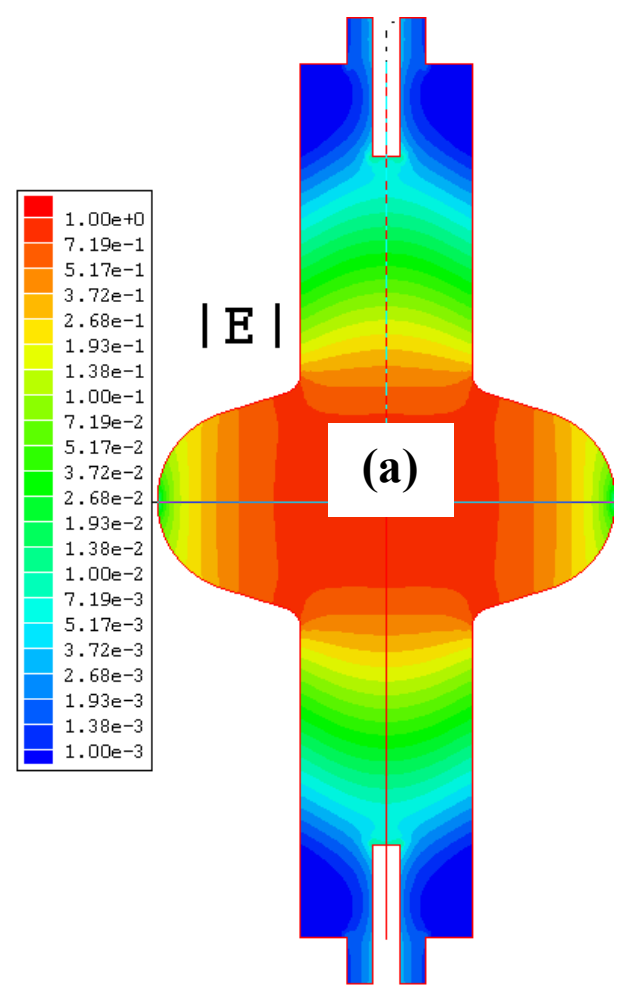

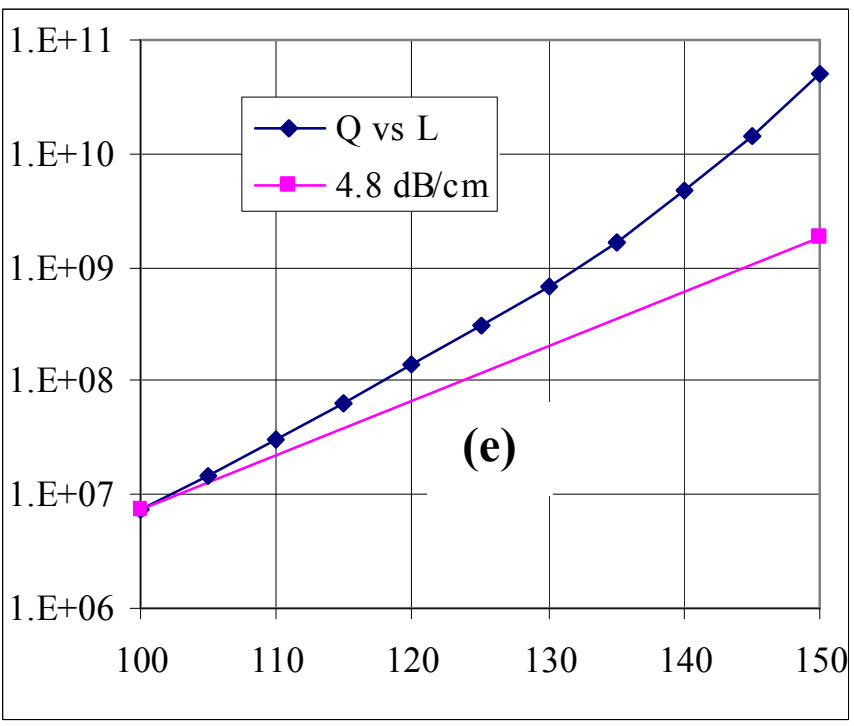

Figure 5 (a) Attenuation for given power coupling (b) Discretization of power probe tip (c) Attenuation for given transmitted coupling (d) Discretization of transmitted probe tip (e) $Q$ vs power probe length (f) $Q_{\text {ext }}$ vs field probe length, (Courtesy of $T$. Khabiboulline)

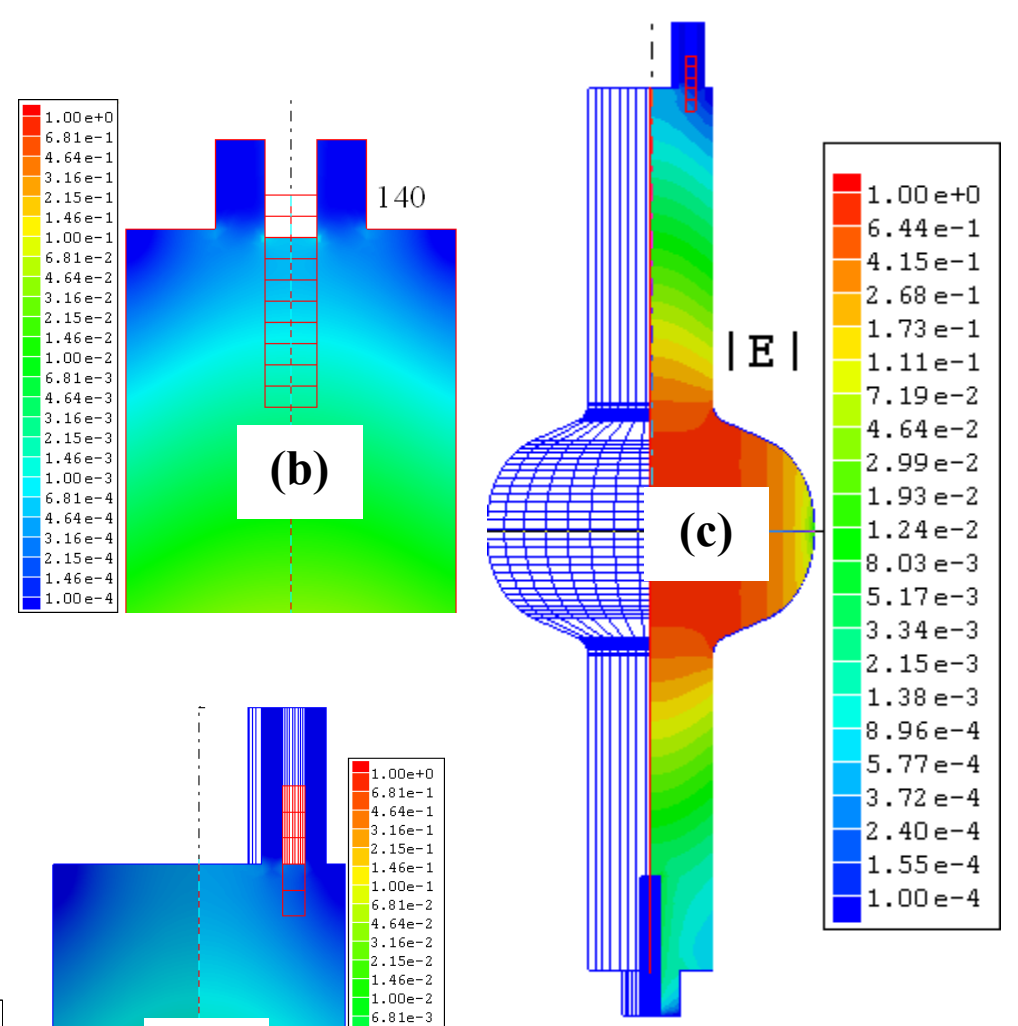

(d)

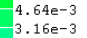




\subsection{Temperature Mapping System:}

A novel temperature mapping system was developed to aid studies on hot spots and quench characteristics of the cavities and also to study field emission. The system comprises of 960 sensors spaced in $\sim 1 \mathrm{~cm} \mathrm{X} 1 \mathrm{~cm}$ grid over the entire outer surface of the cavity to detect any temperature gradient during the cavity test.

The sensing elements used were diodes as opposed to the traditional carbon resistors or cernox RTDs. The diodes were soldered to a kapton circuitry which was epoxied to G10 boards that provide the necessary structural support. For a single cell cavity 60 such boards each carrying 16 working sensors were used. The advantage of using the diodes was substantial reduction in cost, the ability to multiplex the current carrying lines consequently leading to much fewer cables to run through. The system was commissioned at IB1 facility, for more details refer [4].
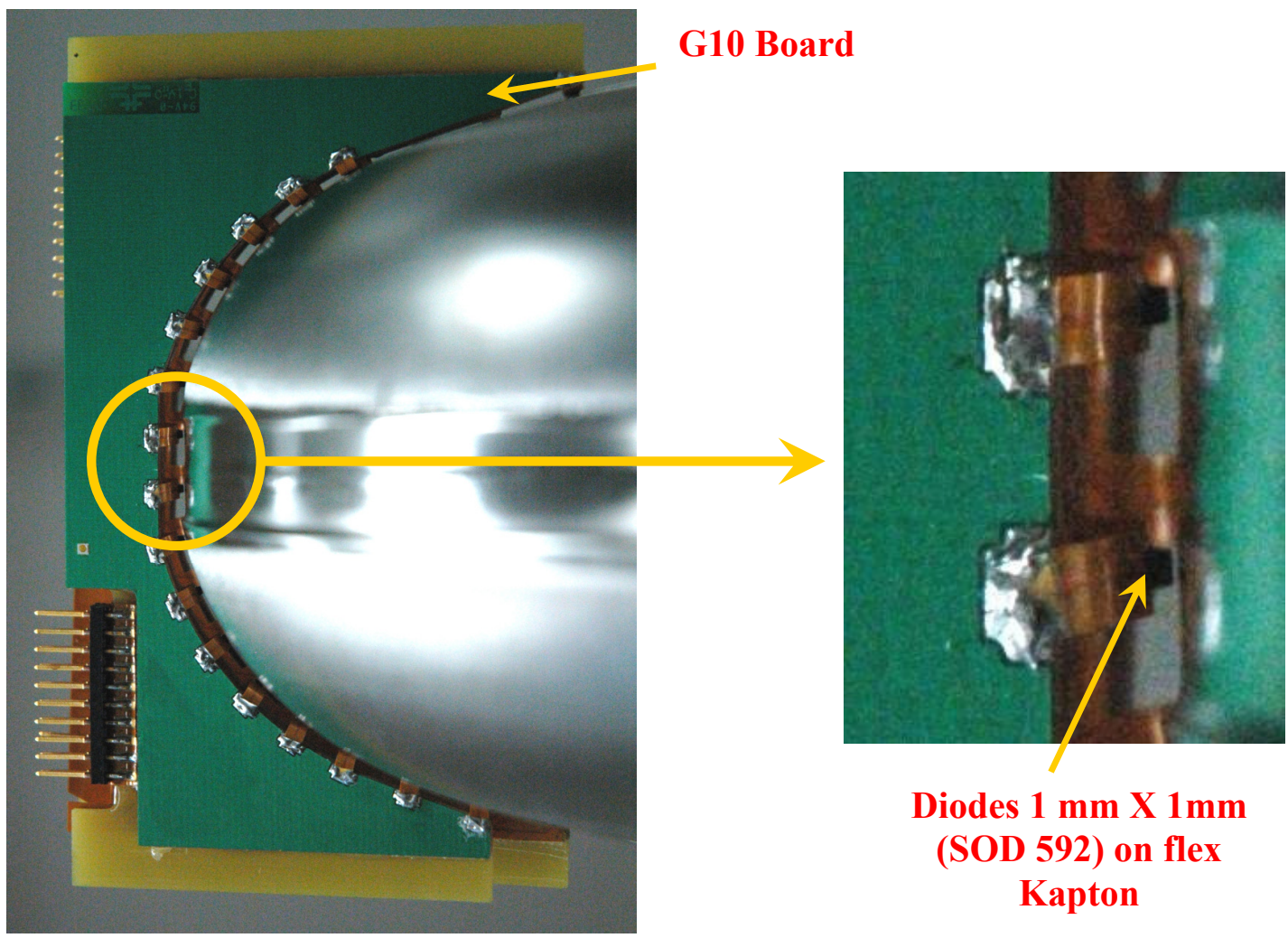

Diodes $1 \mathrm{~mm}$ X $1 \mathrm{~mm}$ (SOD 592) on flex Kapton

Figure 6 A single G10 board with diode sensors attached showing the configuration (courtesy of A. Mukherjee) 


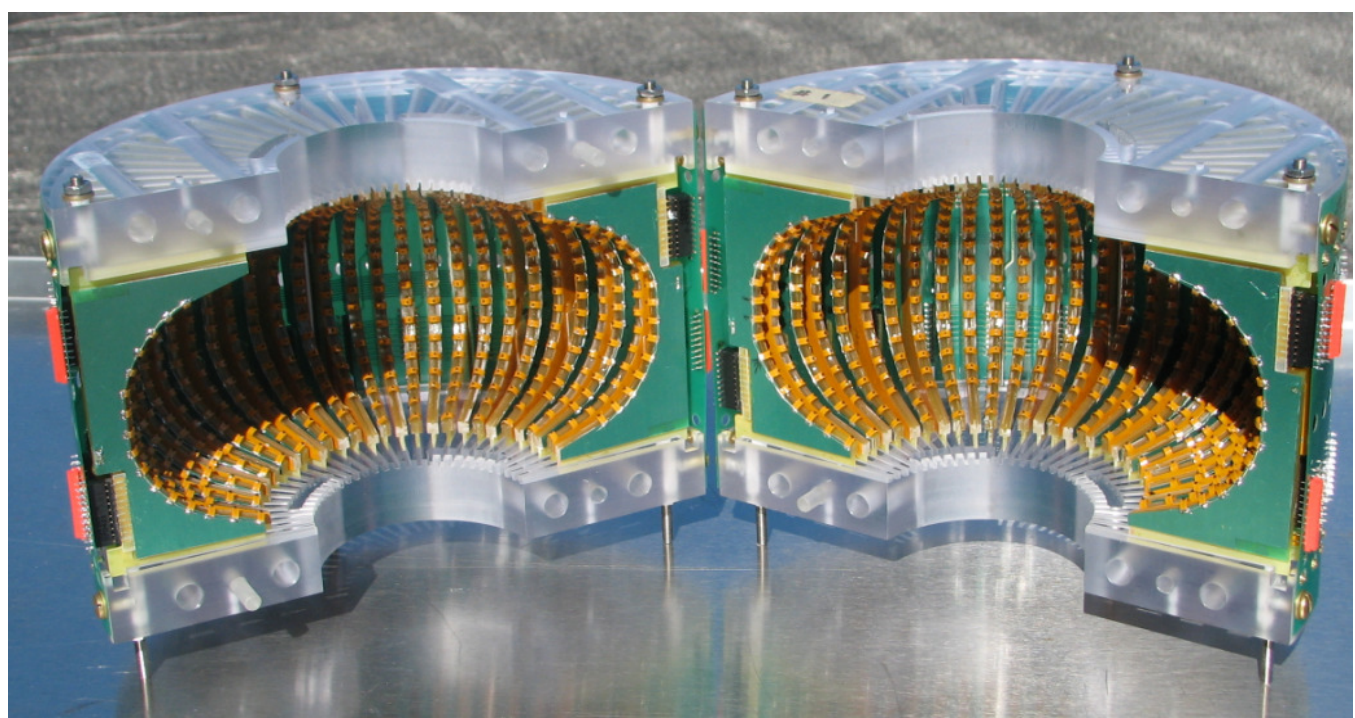

Figure 7 The temperature mapping fixture showing all the sensors installed

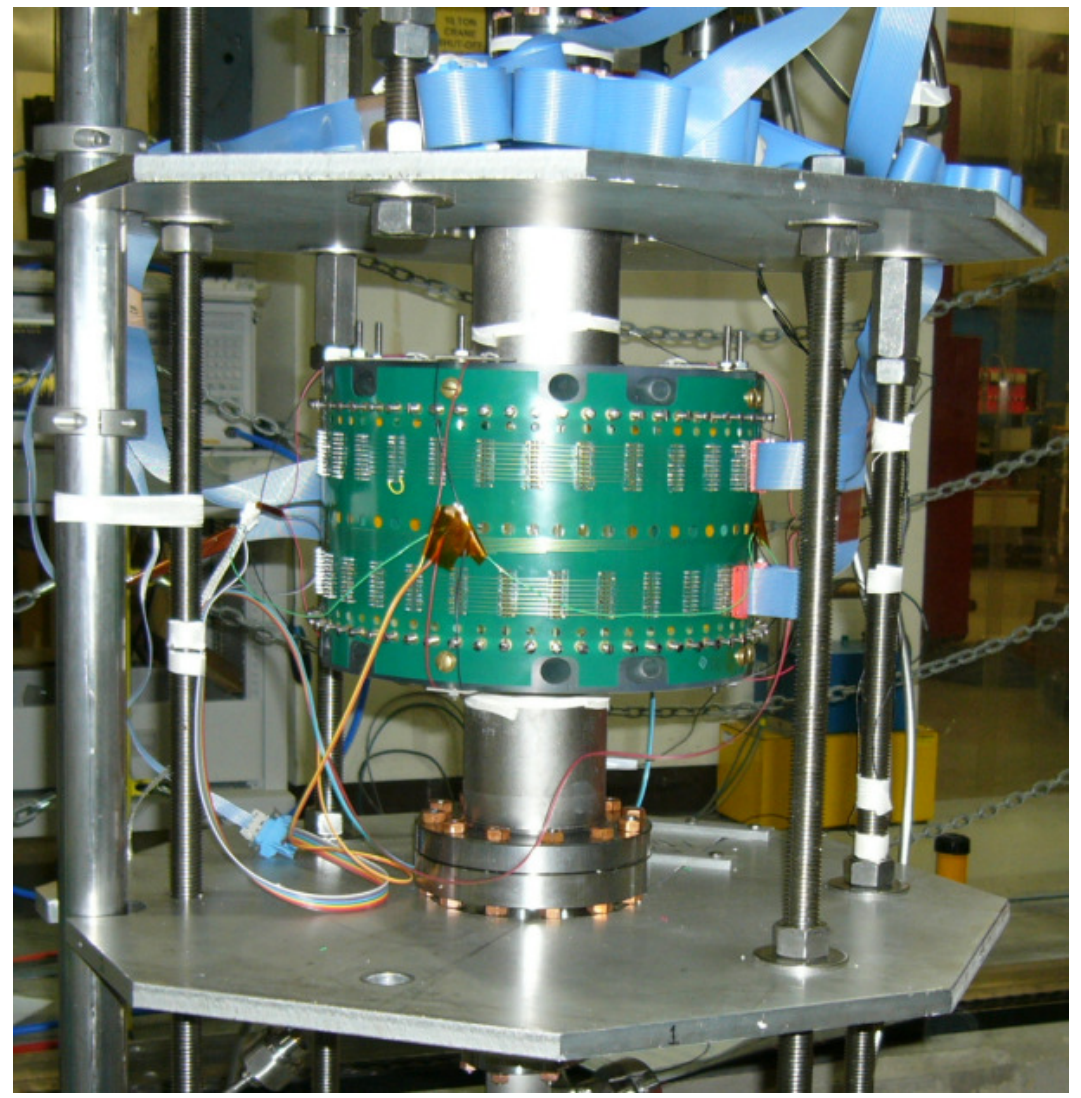

Figure 8 The temperature mapping system installed on a cavity ready to be tested (note: only 4 cables need to be run for a single cell cavity) 


\subsection{Radiation Considerations:}

The higher accelerating gradient of $1.3 \mathrm{GHz}$ single cells compared to $3.9 \mathrm{GHz}$ cavities necessitated the evaluation of the existing radiation shielding. The study was performed using MARS15 Monte Carlo code [5] adopting the results from Fishpact simulations as the source term to provide spatial, energy and angular distributions of field emitted electrons inside the cavity. The study showed the need for additional shielding and as per the recommendations of the radiation safety committee interlocks were placed at the vulnerable locations (shown by simulations) to shut off the RF power in the event of radiation intensity nearing the cut off levels. The radiation data will also be recorded for the initial tests to gain statistics on achievable radiation levels.

\subsection{High Pressure Rinse System:}

The high pressure rinse stand was adapted to fit a $1.3 \mathrm{GHz}$ single cell cavity which is approximately the same length as that of a 9 cell $3.9 \mathrm{GHz}$ cavity. Adapters were designed to seat the larger end flanges of $1.3 \mathrm{GHz}$ cavities. A trial run was performed on a clear plastic model cavity to ensure the sufficiency of the water jet distribution. The jet pressure is about 1200 psi and sufficiently wets the cavity surface.

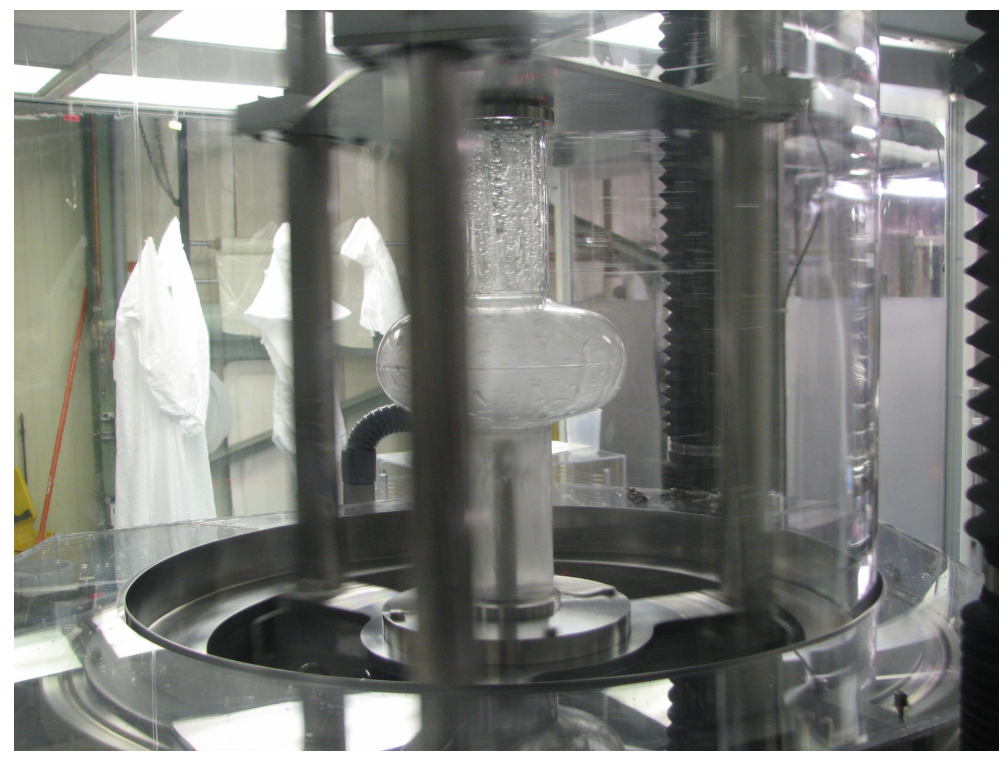

Figure 9 High pressure rinse of clear plastic model cavity 


\subsection{Commissioning:}

The test facility obtained operational readiness clearance during the first quarter of CY 2009 and was commissioned initially with a cavity TE1ACC001 and no active pumping (test personnel M. Ge, T. Khabiboulline and E. Harms). The cavity had been previously tested at the IB1 facility and the test results from both places were almost comparable rendering RF system functional. The cavity performance was limited by field emission. The cavity is being subsequently tested with active pumping and high pressure rinse cycles at $\mathrm{A} 0$.

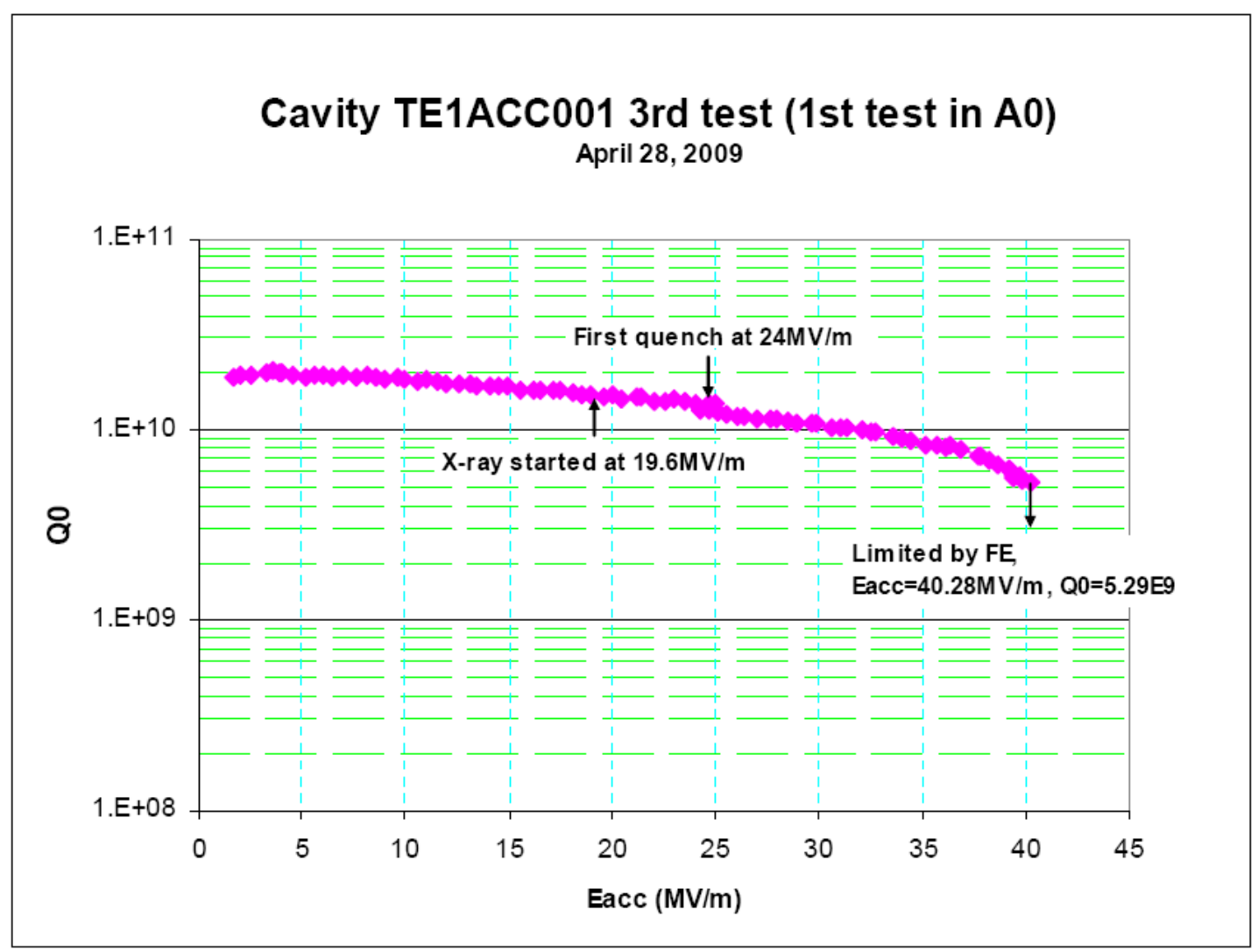

Figure 10 Cavity test result with no active pumping $Q$ vs Eacc (courtesy of M. Ge, G. Wu) 


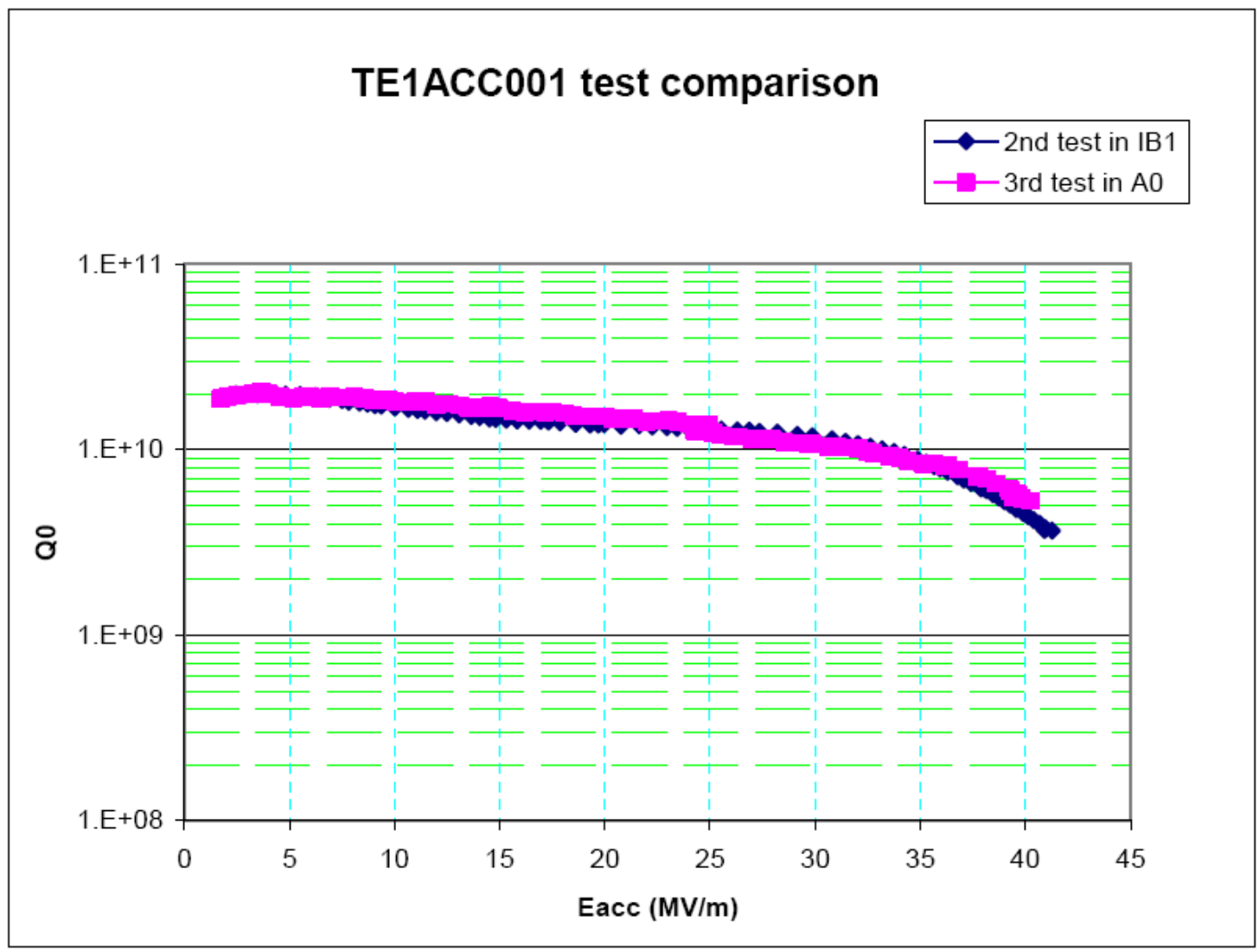

Figure 11 Result comparisons with prior test at IB1 (courtesy of M. Ge, G. Wu)

\section{Summary Note:}

In summary, the infrastructure to test $1.3 \mathrm{GHz}$ single cell cavities has been established at the A0 test facility. The initial tests have helped verify proper functioning of some major components. Currently efforts toward modifying and debugging some system components are underway to enhance the performance of the facility. The project was completed well within the budget limits.

\section{Acknowledgment:}

The author wishes to thank all those who made this project function successfully. Many people have worked on different areas; some of them are: RF system modificationR. Padilla, J. Reid, Coupler design - T. Khabiboulline, Labview program - M. Ge, T-map system electronics - A. Mukherjee, Radiation calculations - I. Rakhnov, C. Ginsburg, G. Wu, Test personnel - M. Ge, T. Khabiboulline, E. Harms, Cavity preparation and fixture 
assembly - A0 and IB1 technicians, ORC - E. Harms. Advisory provided by H. Carter, M. Champion, L. Cooley, G. Ciovati (Jlab), G. Wu, R. Webber, J. Ozelis, A. Rowe, T. Page, C. Ginsburg. Thanks to the radiation safety committee and Tevatron cryogenic safety sub-committee. Thanks also to all other TD (technical division) and AD (accelerator division) personnel involved.

\section{References:}

[1] J. Fuerst, "A0 SRF cavity vertical test dewar", pressure vessel engineering note, vessel number RSB 532, 1999 (original issue).

[2] N. Dhanaraj, "Vertical test stand for $1.3 \mathrm{GHz}$ single cell cavities", amendment \# 5 to engineering note for RSB 532, 2009 (Rev. A).

[3] N. Dhanaraj. "Vertical test stand lifting fixture", below-the-hook lifting devices engineering note, 5520.000-ES-371061, 2009.

[4] N. Dhanaraj, C. Ginsburg, A. Mukherjee, D. Sergatskov, "Multiplexed diode array for temperature mapping of ILC 9 cell cavities”, poster presented, ASC 2008.

[5] N. Dhanaraj, C. Ginsburg, I. Rakhnov, G. Wu, "Radiation shielding for superconducting RF cavity test facility at A0", technical memo TM-2419, Dec 2008 . 
TD-09-022

\section{Appendix A: Proposals and disclaimers submitted to safety panels}

\section{A.1 Pressure rating of top plate vacuum components}

\begin{tabular}{|c|c|c|c|c|c|}
\hline $\begin{array}{l}\text { S. } \\
\text { No. }\end{array}$ & $\begin{array}{l}\text { Dwg. } \\
\text { 457042 } \\
\text { item \# }\end{array}$ & Item & Description & $\begin{array}{l}\text { Manufacturer } \\
\text { /Distributor }\end{array}$ & Pressure Rating \\
\hline 1 & 2 & $\begin{array}{c}\text { Variable } \\
\text { Leak Valve }\end{array}$ & $\begin{array}{l}\text { 2.75" CFF, Part } \\
\text { No. VLVE-1000 }\end{array}$ & Duniway & $15 \mathrm{psi}$ \\
\hline 2 & 12 & Ion Pump & $\begin{array}{l}20 \mathrm{~L} / \mathrm{S} \\
\text { W/Magnets, } \\
\text { Part No. VA-20- } \\
\text { DD-M }\end{array}$ & Duniway & $15 \mathrm{psi}$ \\
\hline 3 & 11 & Ion Gage & $\begin{array}{l}\text { UHV W/ Dual } \\
\text { Iridium } \\
\text { Filament, Part } \\
\text { No. I-NUDE-F }\end{array}$ & Duniway & $\begin{array}{l}15 \mathrm{psi}-\mathrm{OK} \\
\text { Low possibility of filament burnout, } \\
\text { but will remain intact }\end{array}$ \\
\hline 4 & 5 & $\begin{array}{l}\text { Turbo } \\
\text { Pump }\end{array}$ & $\begin{array}{l}\text { V81-M W/ } \\
\text { 2.75" CFF, } \\
\text { Model: } 9698904\end{array}$ & Varian, Inc. & $\begin{array}{l}<2 \text { mTorr. Anything under, pump will } \\
\text { crash. Pump will contain itself, but } \\
\text { blades will be damaged and pump will } \\
\text { not spin up. }\end{array}$ \\
\hline 5 & 6 & $\begin{array}{l}\text { Transpector } \\
\text { RGA }\end{array}$ & $\begin{array}{l}\text { TSP2 series, } \\
\text { Model: H100M }\end{array}$ & Inficon & $\begin{array}{l}15 \text { psi gradual - self containing will } \\
\text { shut off } \\
15 \text { psi sudden - filaments might get } \\
\text { damaged, but instrument itself will not } \\
\text { fall apart. }\end{array}$ \\
\hline 6 & 3 & $\begin{array}{l}\text { Manometer } \\
\text { Transducer }\end{array}$ & $\begin{array}{l}\text { Wide range } \\
1 \mathrm{mTorr}-1500 \\
\text { Torr, SS } \\
\text { diaphragm, Part } \\
\text { No. } 902211- \\
\text { mini }\end{array}$ & $\begin{array}{c}\text { Vacuum } \\
\text { Research Ltd. }\end{array}$ & $\begin{array}{l}\text { Sensor 1: } 15 \mathrm{psi}+\sim 5 \% \\
\text { Sensor 2: } 300-400 \mathrm{psi}\end{array}$ \\
\hline 7 & 4 & $\begin{array}{l}\text { Angle } \\
\text { Valve }\end{array}$ & $\begin{array}{l}\text { All Metal, Part } \\
\text { No. 54032- } \\
\text { GE02-0002 }\end{array}$ & VAT & $\begin{array}{l}30 \mathrm{psi} \text {-valve gate } \\
15 \mathrm{psi} \text { - valve opening }\end{array}$ \\
\hline 8 & 7 & $\begin{array}{l}\text { Membrane } \\
\text { Gas Filter }\end{array}$ & $\begin{array}{l}\text { 0.01 Micron, } \\
\text { Part No. 6190- } \\
\text { T4FF }\end{array}$ & $\begin{array}{l}\text { Matheson Tri- } \\
\text { Gas }\end{array}$ & $1000 \mathrm{psi}$ \\
\hline 9 & 19 & Burst Disk & $\begin{array}{l}\text { Mini CFF, Part } \\
\text { No. } 420030\end{array}$ & MDC-Vacuum & $\begin{array}{l}15 \text { psi }-25 \text { psi, will be replaced by a } 9 \\
\text { psi }-11.5 \text { psi disk soon, part no. } \\
420032\end{array}$ \\
\hline
\end{tabular}




\title{
A.2 A0 North Cave Operation for $1.3 \mathrm{GHz}$ Single-Cell R\&D
}

\author{
E. Harms
}

4 February 2009

The A0 North Cave SCRF test stand is being upgraded to support R\&D on single cell superconducting RF cavities. R\&D in this case consists of powered tests of bare single cell cavities at temperatures as low as $1.8 \mathrm{~K}$ with up to 500 Watts of input power to measure performance parameters such as gradient, Q, field emission, and surface resistance. This program is important to test various cavity processing schemes, material properties, etc. in order to maximize the gradient of full scale superconducting cavities as well as determine an ideal processing protocol.

The main functionality of the stand is to remain the same:

- interlocked, shielded cave for housing the devices under test

- portable dewar within which the cavities rest for cold tests (as low as 1.8K); dewar fed liquid helium cryogenics system

- in-place detectors to monitor x-rays and shut-off the RF system if pre-set limits are exceeded

- local controls system and instrumentation racks with Labview-based test applications.

Enhancements to support these tests include:

- a new top plate/cavity support frame built. The top plate has been successfully pressure tested

- addition of a solid state RF amplifier to provide up to 500Watts to the cavity under test. The RF distribution system is also modified to retain current functionality while affording this upgraded power capability.

Because of the higher power capability, it has been necessary to re-asses the North Cave shielding against $\mathrm{x}$-rays. This assessment is complete and it has been determined that relocation of a limited set of scarecrows already in the cave as well as limiting access to the roof of the cave during operation will permit these tests to occur without compromising personnel safety 
TD-09-022

\title{
A.3 Risk of damage to single-cell cavities during testing at A0
}

\section{番Fermilab}

\author{
Mark Champion, Department Head \\ SRF Development Department \\ Fermilab Technical Division \\ 630.840 .3906 (phone) \\ 630.840 .8036 (fax) \\ champion@fnal.gov
}

March 31, 2009

To: $\quad$ Roger Dixon

From: Mark Champion and Giorgio Apollinari

Subject: Risk of damage to single-cell cavities during testing at A0

Dear Roger,

We hope to begin testing $1.3 \mathrm{GHz}$ single-cell niobium cavities in the $\mathrm{A} 0$ north cave dewar in the near future. The A0 cryogenic safety review panel is reviewing this system and has expressed concern that under rare "upset" conditions, the dewar pressure might exceed the yield strength of the cavity under test. This would cause plastic deformation and detuning of the cavity. Such deformation, if minor, could be repaired by retuning the cavity after its removal from the dewar. In the worst case, the cavity would collapse and would not be repairable.

These single-cell cavities are research and development devices. As such, we are willing to accept the low risk of damage to these cavities during cold testing. We have been operating a similar system at Industrial Building 1 for approximately two years, and there have been no occurrences of cavity damage during cold testing.

The cavity tests at $\mathrm{A} 0$ will help us to develop improved materials and processing techniques. The potential for performance improvements and cost savings is substantial with respect to Project $X$ and far outweighs the risk to these cavities, which cost less than $\$ 15 \mathrm{k}$ each.

Sincerely,
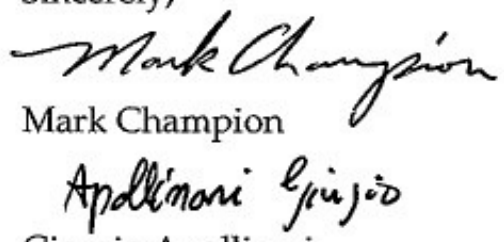

Giorgio Apollinari

cc:

Elvin Harms

Bill Cooper

Fermi National Accelerator Laboratory / Kirk Road and Pine Street / P.O. Box 500 / Batavia, IL 60510/630.840.3000/ www,fnal.gov / fermilab (-) fnal.gov W. Office of Science / U.S. Department of Energy / Managed by Fermi Research Alliance, UC 
TD-09-022

Appendix B: Recommendations and approvals from safety panels

\title{
B.1 AD Radiation safety review recommendation
}

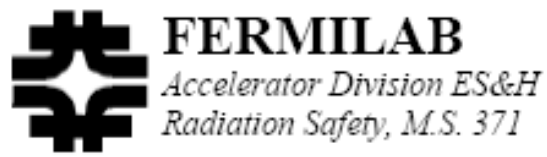

\author{
Date: $\quad$ January 8, 2009 \\ To: $\quad$ Radiation Safety Files \\ From: $\quad$ Gary Lauten \\ Subject: $\quad \mathrm{AD}$ Radiation Safety review of proposal to conduct superconducting RF Cavity \\ tests at $\mathrm{A} 0$. \\ Reference: Radiation Shielding for Superconducting RF Cavity Test Facility at A0 - \\ Fermilab-TM-2419-APC-TD
}

\begin{abstract}
Summary: AD Radiation Safety review of the shielding requirements for A0 North Cave indicates that at the maximum theoretical dark current the shielding is insufficient. However, operating experience that indicates the dose rates from these cavities are typically much lower, and performing additional calculations of the required shielding using $1 \%$ of the maximum theoretical current as a more realistic source term indicates the shielding is still somewhat insufficient, especially in the forward direction (vertical to the cave roof). Therefore, it was determined that placing interlocked detectors at appropriate locations will be acceptable because typical cavities operate with a much lower dose rate ( $90 \%$ of cavities have dose rates of less than $600 \mathrm{mrem} / \mathrm{hr}$ at 1 meter), and high dose rates are rare events that typically are self-limiting because a sparking cavity will lose its field integrity and shut down.
\end{abstract}

AD Radiation Safety calculations using NCRP \#51 of the required shielding estimates that $4.86^{\circ}$ of concrete shielding is required for the roof over the superconducting RF cavity, and 2.92 ' of concrete for the wall adjacent to the cavity. These estimates assume that less than $1 \%$ of the electrons are able to optimally accelerate within the RF field to reach $3.7 \mathrm{MeV}$, and produce bremmstrahlung $\mathrm{x}$-rays. The theoretical value of the current from TM-2419 is $1.1 \mathrm{~mA}$, and $1 \%$ of $1.1 \mathrm{~mA}$ is $0.011 \mathrm{~mA}$. These incidental electrons are produced by anomalies in the cavity geometry and imperfections in the cavity walls which create dark current conditions within the cavity.

Similar estimates of the required shielding assuming all of the electrons at current of $1.1 \mathrm{~mA}$ yields 6.94' of concrete shielding for the roof over the cavity, and 4.26' for the concrete wall adjacent to the cavity. However, experience indicates it is not likely that all of the electrons constituting the current of $1.1 \mathrm{~mA}$ are able to be produced and accelerated in the optimum path within the cavity to produce $\mathrm{x}$-rays. As with other cavity shielding calculations, it is assumed that less than $1 \%$ of the electrons are able to reach the optimum pathway within the cavity to 


\section{ב FERMILAB \\ Accelerator Division ES\&H \\ - Radiation Safety, M.S. 371}

produce the maximum energy of $x$-rays. Therefore, the shielding estimates using $1 \%$ of the maximum dark current $(1.1 \mathrm{~mA})$ is deemed appropriate and conservative.

For comparison, Fermilab-TM-2419-APC-TD estimates that adding $10 \mathrm{~cm}\left(3.93^{\prime \prime}\right)$ to the wall and the roof above the cavity are sufficient to reduce the dose rate to "an acceptable level of 5 mrem/hr." The wall currently has 30 " of concrete (with the minimum dimension of the "Q" block which is 18 " plus the thickness of the " $\mathrm{K}$ " block which is 12 "). The MARS calculation assumed a Q block thickness of 24", which is not conservative. The calculation should have used 18" thickness for the "Q" block which is more conservative. The roof currently is 36 " thick of concrete. It is also incorrect that $5 \mathrm{mrem} / \mathrm{hr}$ is acceptable as a design goal on the side of the cave and on the roof. Based on past precedent in $\mathrm{AD}$, the design goal should be $1 \mathrm{mrem} / \mathrm{hr}$ at 1 ' outside the walls, and $5 \mathrm{mrem} / \mathrm{hr}$ on the roof.

The paper Fermilab-TM-2419-APC-TD also documents historically measured dose rates from RF superconducting cavities at DESY. The dose rate was "less than $600 \mathrm{mrem} / \mathrm{hr} 90 \%$ of the time. The maximum dose rate ever measured was $1500 \mathrm{mrem} / \mathrm{hr}$."

We have reviewed the issues associated with this proposal and have recommendations. There are 2 interlocked "scarecrow" radiation detectors in the A0 north cave that can be relocated and mounted near the cavity. Since it is assumed that only $10 \%$ of the cavities are expected to have dose rates greater than $600 \mathrm{mrem} / \mathrm{hr}$, these two detectors can be placed logistically to disable the system and minimize exposure outside the existing cave. This temporarily delays the need for additional shielding until we have understood the potential dose rates associated with operating in this configuration. Then if additional shielding is needed we can justify the time and expense.

In addition, the A0 North Cave roof will need to be locked and posted as a Radiation Area. This posting requirement may be relaxed as operating experience is gained over time. 
TD-09-022

\title{
B.2 Initial recommendation from cryogenic safety panel
}

\section{FFermilab}

April 3, 2009

\author{
To: $\quad$ Roger Dixon \\ Head, Accelerator Division \\ From: W. E. Cooper \\ Chairman, Tevatron Cryogenic Safety Review Panel
}

Subject: Recommendations regarding testing of $1.3 \mathrm{GHz}$ superconducting RF cavities at $\mathrm{A} 0$

Dear Roger,

The Panel members have reviewed testing of a $1.3 \mathrm{GHz}$ superconducting RF (SRF) cavity within RSB532 at $\mathrm{A} 0$ and have discussed our conclusions with Elvin Harms, who contacted us initially. SRF cavities with a greater surface area, but different geometry, have been tested successfully in RSB532. We have inspected the installation and received updated documentation on the relief system for RSB532 which demonstrates that the relief system will provide adequate protection to RSB532. We have also received a copy of a memo from Mark Champion and Giorgio Apollinari to you regarding the risk of damage to single-cell cavities during $\mathrm{A} 0$ testing. In that memo, they accept the low risk of damage to cavities during cold testing.

We have received a drawing showing "top-plate" component locations and a top plate component listing with pressure ratings. We haven't received a pressure rating for the Inficon RGA transpector. The Varian turbo pump could sustain internal damage if a cavity fails. While we believe the likelihood of a cavity failure is low, you should be aware of the possibility of damage to those two components.

(1) We understand that lower pressure burst disks, though not needed to provide protection to RSB532, will be installed on the relief system of that vessel in order to provide increased protection to a cavity and its vacuum system under upset conditions.

(2) We understand that the burst disk of the cavity vacuum system will be replaced with one having a lower burst pressure to lessen the potential for damage to vacuum system components.

(3) We understand that the flow from all burst disks and the cavity system vacuum pump will be vented outside the $\mathrm{A} 0$ North Cave to mitigate oxygen deficiency hazards.

We note that issues addressed by items (1) - (3) do not occur if a cavity is isolated from the cavity vacuum pumping system. Accordingly, we recommend that you authorize operation of the A0 North Cave system for testing of $1.3 \mathrm{GHz}$ SRF cavities within RSB532 if the cavity is isolated from the cavity pumping system. Once items (1) - (3) have been addressed, we recommend that approval be extended to include testing with the cavity connected to its pumping system

Regards,

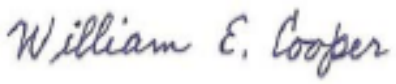

W. E. Cooper,

On behalf of the Tevatron Cryogenic Safety Review Panel 
cc:

\author{
J. E. Anderson, Jr. \\ G. Apollinari \\ M. Champion \\ N. Dhanaraj \\ E. Harms \\ A. Klebaner \\ T. Page \\ Review Panel Members \\ (W. Cooper, P. Hurh, R. H. Lewis, B. Norris, T. Peterson)
}

\title{
B.3 Division head authorization for initial testing
}

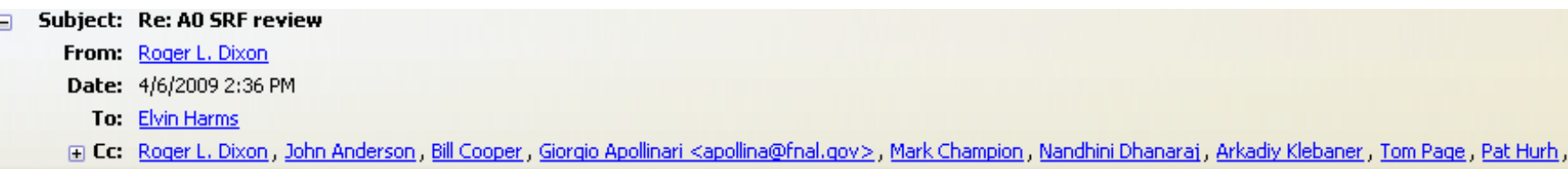

Elvin,

The Tevatron Cryogenic Safety Review Panel has recommended that I authorize operation of the A0 North Cave system for testing of the $1.3 \mathrm{GHz}$ SRF cavities subject to isolating the cavities from the vacuum pumping system. (See their memo to me attached below.) You are hereby authorized to operate the system subject to this condition.

Roger

From: Bill Cooper scooper@inal.gov>

Date: April 6, 2009 11:05:26 AM CDT

To: "Roger L. Dixon" <roger@inal.govs

Cc: jea@fnal.gov, Giorgio Apollinari sapollina@final.gows, champion@fnal.gov, Nandhini Dhanaraj sdhanaraj@final.gov, Elvin Harms sharms@fnal.govs, Arkadiy

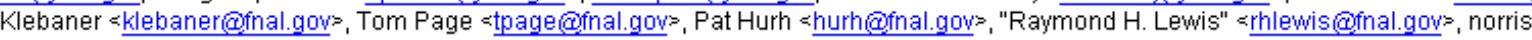
snorris@final.gov>, Tom Peterson stommy@final.gov>, Bill Cooper scooper@final.gov»

Subject: A0 SRF review

Dear Roger,

A recommendation letter is attached.

Regards.

Bill

A0_north_cavi...03_signed.pdf Part 1.1.3


TD-09-022

\section{B.4 Recommendation for operation with active pumping from cryogenic}

\section{safety panel}

\section{节Fermilab}

May 13, 2009

To: $\quad$ Roger Dixon

Head, Accelerator Division

From: W. E. Cooper

Chairman, Tevatron Cryogenic Safety Review Panel

Subject: Recommendations regarding testing of $1.3 \mathrm{GHz}$ superconducting RF cavities at A0

Dear Roger,

The Panel members were informed by Elvin Harms that a $1.3 \mathrm{GHz}$ superconducting RF cavity has been successfully tested at A0 with passive pumping and that system modifications have been made to allow testing with active pumping. The full Panel inspected the installation yesterday, May 12. Lower pressure rupture disks set to a pressure of 7-11 psi have been installed and vented outside the A0 North Cave. Subsequent to the inspection, we received an operating procedure written by E. Harms and W. Muranyi which addresses the use of active pumping during cavity conditioning. The procedure includes provisions for venting vacuum pumps outside the Cave during warm and cold cavity conditioning. All of our recommendations associated with active pumping during cavity testing have now been satisfied and we believe that, following the added procedure, cavities can now be tested safely with active pumping during cavity conditioning. Therefore, we recommend that you authorize the testing of $1.3 \mathrm{GHz}$ superconducting RF cavities with the use of active pumping during cavity conditioning.

Regards,

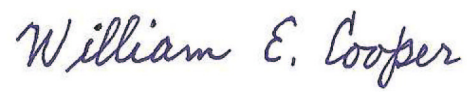

W. E. Cooper,

On behalf of the Tevatron Cryogenic Safety Review Panel

cc:

J. E. Anderson, Jr.

G. Apollinari

M. Champion

N. Dhanaraj

E. Harms

A. Klebaner

T. Page

Review Panel Members

(W. Cooper, P. Hurh, R. H. Lewis, B. Norris, T. Peterson) 


\section{B.5 Division head authorization for testing with active pumping}

$\square$ Subject: Re: A0 SRF review

From: Roger L. Dixon

Date: $5 / 14 / 2009$ 9:32 AM

To: Elvin Harms

๑ Cc: Roger L. Dixon, John Anderson, Giorqio Apollinari <apollina@fnal.qov>, Mark Champion, Nandhini Dhanaraj, Bill Cooper, Arkadiy Klebaner, Tom Paqe, Pat Hurh,

Elvin,

I have received a recommendation from the Tevatron Cryogenic Review Panel concerning the testing $1.3 \mathrm{GHz}$ superconducting RF cavities. The panel recommends that these tests can be carried with the use of "active Pumping during cavity conditioning. Therefore, I authorize you to carry out these tests subject to the conditions stated in the appended memo to me from William Cooper.

Roger

On May 13, 2009, at 4:30 PM, Bill Cooper wrote:

$\langle$ Ho_north_cavity_test_090513_signed.doc〉

A0_north_cavi...13_signed.doc Part 1.3

